\title{
Aktif Karbon ile Sulu Çözeltilerden Amoksisilin Giderimi: Kinetik ve Denge Çalışmaları
}

\author{
Elif Tümay Özer ${ }^{1}$ \\ ${ }^{1}$ Bursa Uludağ Üniversitesi, Fen-Edebiyat Fakültesi, Kimya Bölümü, Bursa, Türkiye (ORCID: 0000-0002-5225-0146)
}

(İlk Geliş Tarihi 15 Şubat 2020 ve Kabul Tarihi 31 Mart 2020)

(DOI: 10.31590 /ejosat.697040)

\begin{abstract}
ATIF/REFERENCE: Tümay Özer, E.. (2020). Aktif Karbon ile Sulu Çözeltilerden Amoksisilin Giderimi: Kinetik ve Denge
\end{abstract} Çalışmaları. Avrupa Bilim ve Teknoloji Dergisi, (18), 833-839.

$\ddot{\mathbf{O} z}$

Amoksisilin (AMX), çok çeşitli mikroorganizmalara karşı geniş bir spektrumda kullanımı ve bakterilere karşı yüksek direnç göstermesi nedeniyle yaygın olarak tüketilen ticari bir antibiyotiktir. Bu nedenle özellikle çevresel sulardan uzaklaştırılması önemli olan bir bileşiktir. Bu çalışmada, ticari olarak temin edilen aktif karbon, sulu fazdan AMX uzaklaştırılması için kullanıldı. Adsorpsiyon prosesini etkileyen $\mathrm{pH}$, başlangıç AMX derişimi, sıcaklık ve temas süresi parametrelerinin adsorplanan AMX miktarına etkisi incelendi. Başlangıç AMX derişiminin etkisi 3-500 mg/L derişim aralığında incelendi. Adsorpsiyona pH etkisi ise 2-10 aralığında araştırıldı. Adsorpsiyon işlemleri üç farklı sıcaklık için $\left(10^{\circ} \mathrm{C}, 25^{\circ} \mathrm{C}\right.$ and $\left.40^{\circ} \mathrm{C}\right)$ gerçekleştirildi. Maksimum AMX adsorpsiyon kapasitesi pH değeri 3 olan sulu çözeltide $223,9 \mathrm{mg} / \mathrm{g}\left(25^{\circ} \mathrm{C}\right)$ olarak hesapland1. Adsorpsiyonun endotermik bir doğası olduğu belirlendi ve artan sıcaklıkla adsorpsiyon kapasitesinde artış gözlemlendi. Elde edilen adsorpsiyon verilerinin Langmuir izotermi ile uyum sağladığı belirlendi. Adsorpsiyonun yalancı-ikinci-derece kinetik modele uyum gösterdiği bulundu. Ayrıca aktif karbon, AMX ile kirletilmiş çeşme suyundan antibiyotiğin giderimi için etkin olarak kullanıldı.

\section{Removal of Amoxicillin in Aqueous Solution by an Activated Carbon: Kinetic and Equilibrium Studies}

\begin{abstract}
Amoxicillin (AMX) is a commercial antibiotic commonly consumed due to its wide spectrum of use against a wide variety of microorganisms and its high resistance to bacteria. For this reason, it is a compound that is especially important to be removed from environmental waters. In this study, commercially activated carbon was used to remove AMX from the aqueous phase. The effect of $\mathrm{pH}$, initial AMX concentration, temperature and contact time parameters affecting the adsorption process on the adsorbed AMX amount was determined. The effect of the initial AMX concentration was examined in the range of 3-500 $\mathrm{mg} / \mathrm{L}$. The $\mathrm{pH}$ effect on adsorption was investigated in the range of 2-10. Adsorption processes were performed for three different temperatures $\left(10^{\circ} \mathrm{C}, 25^{\circ} \mathrm{C}\right.$ and $\left.40{ }^{\circ} \mathrm{C}\right)$. The maximum AMX adsorption capacity was calculated as $223.9 \mathrm{mg} / \mathrm{g}\left(25^{\circ} \mathrm{C}\right)$ in an aqueous solution with a pH of 3 . Adsorption was determined to have an endothermic nature and an increase in adsorption capacity was observed with increasing temperature. Adsorption isotherms compatible with Langmuir isotherm. By evaluating the kinetic data, it was found to be compatible with the pseudosecond degree kinetic model. Activated carbon was also used effectively for AMX removal from tap water contaminated with AMX.
\end{abstract}

Keywords: Amoxicillin, Activated carbon, Removal.

\footnotetext{
${ }^{1}$ Sorumlu Yazar: Bursa Uludağ Üniversitesi, Fen-Edebiyat Fakültesi, Kimya Bölümü, Bursa, Türkiye, ORCID: 0000-0002-5225-0146, etumay@uludag.edu.tr
} 


\section{Giriş}

Artan nüfus ile beraber kimyasalların yaygın kullanımı nedeniyle yüzey ve yeraltı sularının kirliliği, dünya çapında giderek daha ciddi bir sorun haline gelmektedir. Farmasötik bileşikler, yaygın kullanımları ve su ortamında uzun vadeli etkileri nedeniyle dünya çapında önemli ve hızla gelişen bir kirletici sınıfını oluşturmaktadır. Antibiyotikler, hem insanlarda hem de hayvanlarda çeşitli bulaşıcı hastalıkları tedavi etmek için yaygın olarak kullanılan bir ilaç grubudur (Garoma ve ark., 2010, Yu ve ark., 2016). Çoğu antibiyotik tamamen metabolize edilemez, kalıntıları ve bozunma ürünleri vücuttan atılır ve sucul ortama çeşitli yollarla girebilir. Antibiyotik kalıntılarına ve metabolitlerine maruz kalmak, çevrede mikroorganizmaların antibiyotik direncinin oluşması, organizmalar için kronik ve akut toksisite gibi çeşitli olumsuz etkilere neden olmaktadır(WHO, 2014, Michael ve ark., 2013).

Amoksisilin (AMX), bakterilere karşı yüksek direnç göstermesi ve çok çeşitli mikroorganizmalara karşı geniş bir spektrumda kullanımı nedeniyle yaygın olarak tüketilen ticari bir antibiyotiktir. AMX'nin çok az bozunduğu ve çevrede biyolojik olarak biriktiği bilinmektedir(WHO, 2014). AMX'nin maksimum biyodegradasyonu, arıtılmış kanalizasyon atık sularında \% 25,03 olarak rapor edilmiştir (Al-Gheethi ve Ismail 2014). Ayrıca farmasötik içerikli atık sulardaki amoksisilin, gıda zincirindeki birçok organizma üzerinde toksik bir etkiye sahip olduğu ve organizmaların fotosentez mekanizmalarını inhibe ettiği bilinmektedir ( Pan ve Ark., 2008). $\mathrm{Bu}$ antibiyotiğin ortamda bulunması durumunda, sucul ve karasal ekosistem üzerinde endokrin bozucu ve büyüme inhibisyonu gibi olumsuz etkilere neden olduğu rapor edilmektedir (Al-Gheethi ve Ismail, 2014; Hughes ve ark., 2016).

Atık sulardan farmasötik maddelerin uzaklaştırılması için ozonlama (Andreozzi ve ark., 2005), membran filtrasyonu (Li ve ark., 2004), fotodegradasyon (Trovó ve ark., 2008) ve biyolojik arıtma (Al-Gheethi ve İsmail, 2014) gibi çeşitli teknikler mevcuttur. Bunların yanısıra uygulama, kolaylık, verimlilik ve maliyet açısından daha avantajlı olan adsorpsiyon tekniği de sıklıkla kullanılmaktadır (Hayati ve ark., 2018). Literatür, aktif karbon (AC) adsorpsiyonunun farklı farmasötikler de dâhil olmak üzere çeşitli su kirleticilerinin giderilmesinde etkili bir yaklaşım olduğunu göstermiştir (Redding ve ark., 2009). Bununla birlikte, antibiyotiklerin aktif karbon üzerindeki adsorpsiyon mekanizması, kullanılan aktif karbon kaynă̆ı üretim prosesi ve adsorban yapısına göre farklılıklar göstermekte ve aydınlatılmasına ilişkin çalışmalar sürdürülmektedir.

$\mathrm{Bu}$ çalışmada, ticari olarak kullanılan toz aktif karbonun sulardan AMX uzaklaştırmasındaki etkinliği değerlendirilmiştir. Adsorpsiyon mekanizmasının aydınlatılması için, adsorpsiyona etki eden AMX derişimi, temas süresi, $\mathrm{pH}$ ve sıcaklık parametreleri incelenmiştir. Adsorpsiyon mekanizması, adsorpsiyon verilerinin farklı izoterm ve kinetik modellere uygulanması ile açıklanmıştır.

\section{Materyal ve Metot}

\subsection{Kimyasallar ve Cihazlar}

Çalışmada kullanılan AMX standardı Sigma-Aldrich (St. Louis, ABD) firmasından temin edilmiştir. Kullanılan tüm kimyasallar analitik saflıktadır. Adsorpsiyon işlemlerinde kullanılan toz aktif karbon Fluka marka olup, Sigma-Aldrich (St. Louis, ABD) firmasından alınmıştır. Ortalama parçacık büyüklüğü $40 \mu \mathrm{m}$ 'nin altındadır. Deneylerde kullanılan ultra saf su, Elga Flex3 ultra saf su cihazı (Veloia Water Solutions \& Technologies, Fransa) kullanılarak üretilmiştir. pH ölçümlerinde cam elektroda sahip, Hanna Instruments pH 211 marka pH metre kullanılmıştır. Batch tipi adsorpsiyon çalışmalarında absorbans takibi için UV-GB spektrofotometresi (UV-1700 Shimadzu) kullanılmıştır. Amoksisilin molekülünün sulu çözeltilerdeki derişimi $272 \mathrm{~nm}$ dalga boyunda kuartz (Hellma 100-QS, 1şık yolu $10 \mathrm{~mm}$ ) küvetler kullanılarak belirlenmişsir.

\subsection{Adsorpsiyon Çalışmaları}

Yaklaşık 1000 mg/L derişimde AMX çözeltisi (stok çözelti), gerekli miktarda AMX katısının saf su içinde çözülmesi ile hazırlanmıştır. Daha sonra stok çözelti, istenen derişimlerde AMX çözeltileri elde etmek için uygun şekilde seyreltilerek kullanılmıştır. Tüm adsorpsiyon çalışmaları aynı deney protokolü kullanılarak kesikli batch modda gerçekleştirilmiştir. Çalışmalarda genel olarak, sıcaklık kontrollü inkübatör sistemi (Heidolph Instruments, $\mathrm{GmbH} \& \mathrm{Co} . \mathrm{KG}$, Schwabach, Almanya) kullanarak sabit sicaklık sağlanmıştır. Toplam 50 mL AMX çözeltilerine uygun miktarlarda aktif karbon $(0,0200 \mathrm{~g})$ ilave edilmiştir. Karışım yaklaşık 2 saat sabit hızda (300 rpm) karıştırılmış ve $0,45 \mu \mathrm{m}$ gözenek büyüklüğüne sahip PVDF filtreden geçirilen sulu faz, UV-GB spektrofotometresi ile analiz edilmiştir. Adsorpsiyon işlemlerinde aktif karbonun t zamanında $\left(\mathrm{q}_{\mathrm{t}}, \mathrm{mg} / \mathrm{g}\right)$ ve dengedeki $\left(\mathrm{q}_{\mathrm{e}}, \mathrm{mg} / \mathrm{g}\right)$ adsorpsiyon kapasitesi aşağıdaki denklemlerden hesaplanmıştır.

$$
\begin{aligned}
& q_{t}=\frac{\left(C_{0}-C_{t}\right)}{m} \times V \\
& q_{e}=\frac{\left(C_{0}-C_{e}\right)}{m} \times V
\end{aligned}
$$

$\mathrm{q}_{\mathrm{t}}$ ve $\mathrm{q}_{\mathrm{e}} \mathrm{t}$ ve dengede adsorpsiyon kapasitesini $(\mathrm{mg} / \mathrm{g}) ; \mathrm{C}_{0}, \mathrm{C}_{\mathrm{t}} \mathrm{ve} \mathrm{C}_{\mathrm{e}}$, sırasıyla başlangıçta, $\mathrm{t}$ zamanında ve dengeki amoksisilin derişimini (mg/ L); m, aktif karbon kütlesini (g); V ise çözeltinin hacmini (L) göstermektedir. 


\subsubsection{Adsorpsiyona pH Etkisi}

Adsorpsiyon kapasitesine etki eden deneysel parametrelerin başında $\mathrm{pH}$ gelmektedir. Bu amaçla sabit derişimde (30 mg/L) AMX içeren farklı $\mathrm{pH}$ değerlerine sahip çözeltilere yaklaşık 0,0200 g aktif karbon eklenmiş ve adsorpsiyon kapasitesindeki değişimler izlenmiştir. Çözeltilerin $\mathrm{pH}$ ayarlamalarında $\mathrm{HCI}$ ve $\mathrm{NaOH}$ çözeltileri kullanılmıştır.

\subsubsection{Adsorpsiyona Derişim Etkisi}

Farklı derişimlerde ve pH 3'de (3-5-10-20-30-50-100-200-300-500 mg/L) AMX çözeltileri hazırlanmış ve ilave edilen 0,0200 g aktif karbon ile farklı sıcaklıklardaki $\left(10^{\circ} \mathrm{C} / 25^{\circ} \mathrm{C} / 35^{\circ} \mathrm{C}\right)$ adsorpsiyon kapasiteleri hesaplanmıştır.

\subsubsection{Adsorpsiyona Süre Etkisi}

Bu amaçla yaklaşık $30 \mathrm{mg} / \mathrm{L}$ derişiminde hazırlanan AMX çözeltilerine $0,0200 \mathrm{~g}$ kadar aktif karbon ilave edilmiş ve farklı süre ve sıcaklıklarda çalışılarak, sulu çözeltilerdeki AMX derişimi tayin edilmiş ve adsorpsiyon kapasitesi belirlenmiştir.

\subsubsection{Adsorpsiyon Çalışmasında Kullanılan İzoterm ve Kinetik Modeller}

$\mathrm{Su}$ ortamındaki bir bileşenin adsorban üzerindeki tutulumunu ifade eden, bir kısmı ampirik birçok izoterm ve kinetik model geliştirilmiştir. Çalışmada kullanılan izoterm ve kinetik modeller Tablo 1'de özetlenmişsir.

Tablo 1. Çalışmada kullanılan izoterm ve kinetik modeller

\begin{tabular}{lll}
\hline Model & Eşitlik & Parametreler \\
\hline Izoterm modelleri &
\end{tabular}

Langmuir

$$
\begin{aligned}
\frac{C_{e}}{q_{e}} & =\frac{1}{Q_{L} K_{L}}+\frac{C_{e}}{Q_{L}} \\
R_{L} & =\frac{1}{1+K_{L} \cdot C_{e}}
\end{aligned}
$$

$\mathrm{q}_{\mathrm{e}} \quad(\mathrm{mg} / \mathrm{g})$ Dengedeki adsorpsiyon kapasitesi

$\mathrm{Q}_{\mathrm{L}} \quad$ (mg/g) Maksimum tek katmanlı adsorpsiyon kapasitesi

$\mathrm{K}_{\mathrm{L}} \quad(\mathrm{L} / \mathrm{mg})$ Langmuir denge sabiti

$\mathrm{R}_{\mathrm{L}} \quad$ Ayırma faktörü

Freundlich

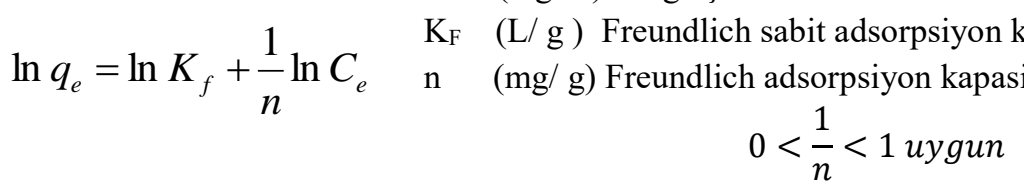

\section{Kinetik modeller}

Yalanc1 birinci derece

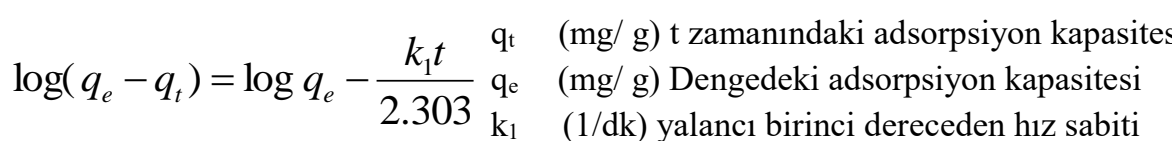

Yalancı ikinci derece

$$
\frac{t}{q_{t}}=\frac{1}{k_{2} q_{e}^{2}}+\frac{1}{q_{e}} t \quad \begin{aligned}
& \mathrm{q}_{\mathrm{t}} \\
& \mathrm{q}_{\mathrm{e}} \\
& \begin{array}{l}
(\mathrm{mg} / \mathrm{g}) \mathrm{t} \text { zamanındaki adsorpsiyon kapasitesi } \\
(\mathrm{mg} / \mathrm{g}) \text { Dengedeki adsorpsiyon kapasitesi } \\
(\mathrm{g} / \mathrm{mg} \mathrm{dk}) \text { yalanc1 ikinci dereceden hı sabiti }
\end{array}
\end{aligned}
$$

\subsection{Gerçek Örneklerde Giderim Çalışmaları}

Gerçek su örneklerine (musluk suyu) iki farklı derişimde (20 ve $200 \mathrm{mg} / \mathrm{L}$ ) AMX standardı ilave edilerek, farklı aktif karbon miktarları $(0,0200-0,0400-0,0600 \mathrm{~g})$ ile oda sıcaklı̆̆ında $\left(25^{\circ} \mathrm{C}\right)$ AMX giderim işlemi gerçekleștirilmiştir. Her numune için üç tekrar deney yapılmıştır. Giderim verimi aşağıdaki eşitlik ile hesaplanmıştır.

$$
\% \text { Verim }=\frac{\left(C_{0}-C_{t}\right)}{C_{0}} \times 100
$$

burada $\mathrm{C}_{0}$ ve $\mathrm{C}_{\mathrm{t}}(\mathrm{mg} / \mathrm{L})$ başlangıç ve $\mathrm{t}(\mathrm{dk})$ zamanında çözeltide kalan AMX derişimine karşılık gelmektedir. 


\section{Araştırma Sonuçları ve Tartışma}

\subsection{Adsorpsiyona pH etkisi}

Çözelti pH’ı adsorpsiyon çalışmalarında adsorban yüzeyi ve analit yükünü etkileyen önemli bir parametredir. Amoksisilin proton verici gruplarının $(-\mathrm{COOH}$ ve $-\mathrm{OH})$ ve proton alıcı grubunun $\left(-\mathrm{NH}_{2}\right)$ etkisiyle amfoterik bir moleküldür. AMX molekülü 2,4 $(-\mathrm{COOH}), 7,4$ $\left(-\mathrm{NH}_{2}\right)$ ve 9,6 $(-\mathrm{OH}) \mathrm{pKa}$ değerlerine sahiptir. Bu sayede ortam pH'ına bağlı olarak katyon, yüksüz (zwitterion) ve anyonik formlarda bulunabilir. AMX molekülünde bulunan karboksil grubu (-COOH), asidik çözelti (pH 2-6) içerisinde karboksilat $\left(-\mathrm{COO}^{-}\right)$olarak, amin grubu ise $-\mathrm{NH}_{3}{ }^{+}$yapısında bulunur. Bu sayede oluşan nötr yüke sahip yap1 sayesinde, $\mathrm{pH}$ 3'de en yüksek adsorpsiyon kapasitesine ulaşılmıştır. Şekil 1'de görüldüğü gibi ortam pH'ının adsorpsiyon kapasitesi üzerine etkisi oldukça azdır. Bu da aktif karbon ile AMX etkileşiminin elektrostatik etkileşimden çok, zayıf Wander-Waals etkileşimlerine dayanması ile açıklanabilir. Her iki yapı arasında aromatikliğin getirdiği $\pi$ - $\pi$ etkileşimleri olabilir. Böylelikle analit ve adsorbanın yüzey yükünden bağımsız bir etkileşim oluşur. Bu sonuç her çözelti pH’ında çalışmayı mümkün kılmaktadır (Li ve ark., 2017, Zandipak ve Sobhanardakani, 2018).

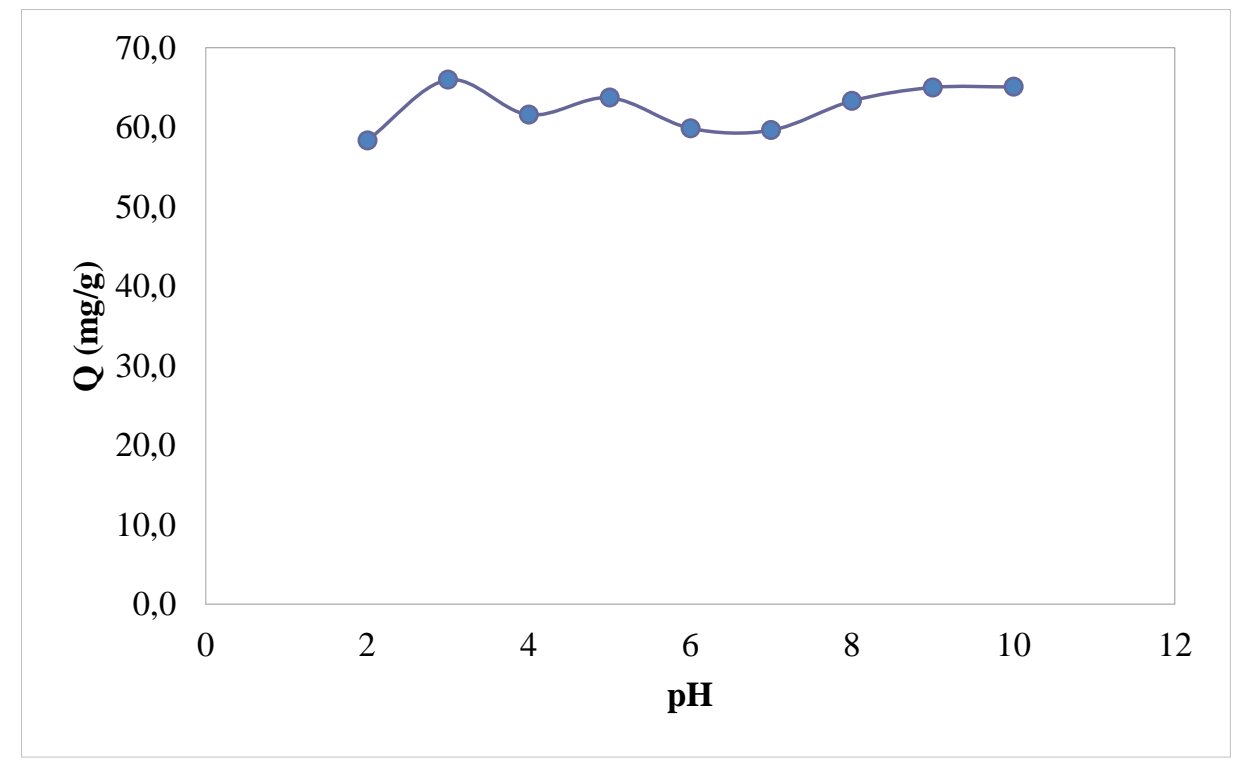

Şekil 1. Adsorpsiyona pH etkisi

\subsection{Adsorpsiyona Derişim Etkisi}

İlaç içeriğinin adsorpsiyon kapasitesi üzerindeki etkisi 3 ila $500 \mathrm{mg} / \mathrm{L}$ başlangıç AMX derişim aralığında araştırılmıştır. Aktif karbon tarafından AMX adsorpsiyonu için elde edilen veriler Şekil 2'de sunulmuştur. Şekil 2'den görüldüğü gibi, AMX başlangiç derişiminde $3 \mathrm{mg} / \mathrm{L}$ 'den $500 \mathrm{mg} / \mathrm{L}^{\prime}$ ye artışla, adsorbe edilen $\mathrm{AMX}\left(\mathrm{q}_{\mathrm{e}}\right.$ ) değerleri de $10^{\circ} \mathrm{C}$ için $5,1^{\prime} \mathrm{den} 207,8^{\prime}$ e; $25^{\circ} \mathrm{C}$ için $5,2^{\prime} \mathrm{den} 223,9^{\prime}$ a; $40^{\circ} \mathrm{C}$ için ise $7,1^{\prime}$ 'en $227,8^{\prime}$ e yükselmiştir.

Adsorpsiyon denge çalışmaları için lineer Langmuir ve Freundlich izoterm modellerinden yararlanılmıştır. Langmuir izotermi genellikle çözünen maddenin sıvı çözeltilerden adsorpsiyonunu açıklamak için kullanılır. Bu modelin varsayımları arasında, adsorbat moleküllerinin birbiri ile etkileşiminin olmadığı ve sınırlı sayıda özdeş bölgeye sahip homojen bir yüzeyde tek tabakalı adsorpsiyon vardır (Langmuir, 1918). Freundlich izoterm yaklaşımı ise, adsorpsiyon davranışı heterojen bir yüzeyde gerçekleştiğini kabul etmektedir (Freundlich ve Heller, 1939). 


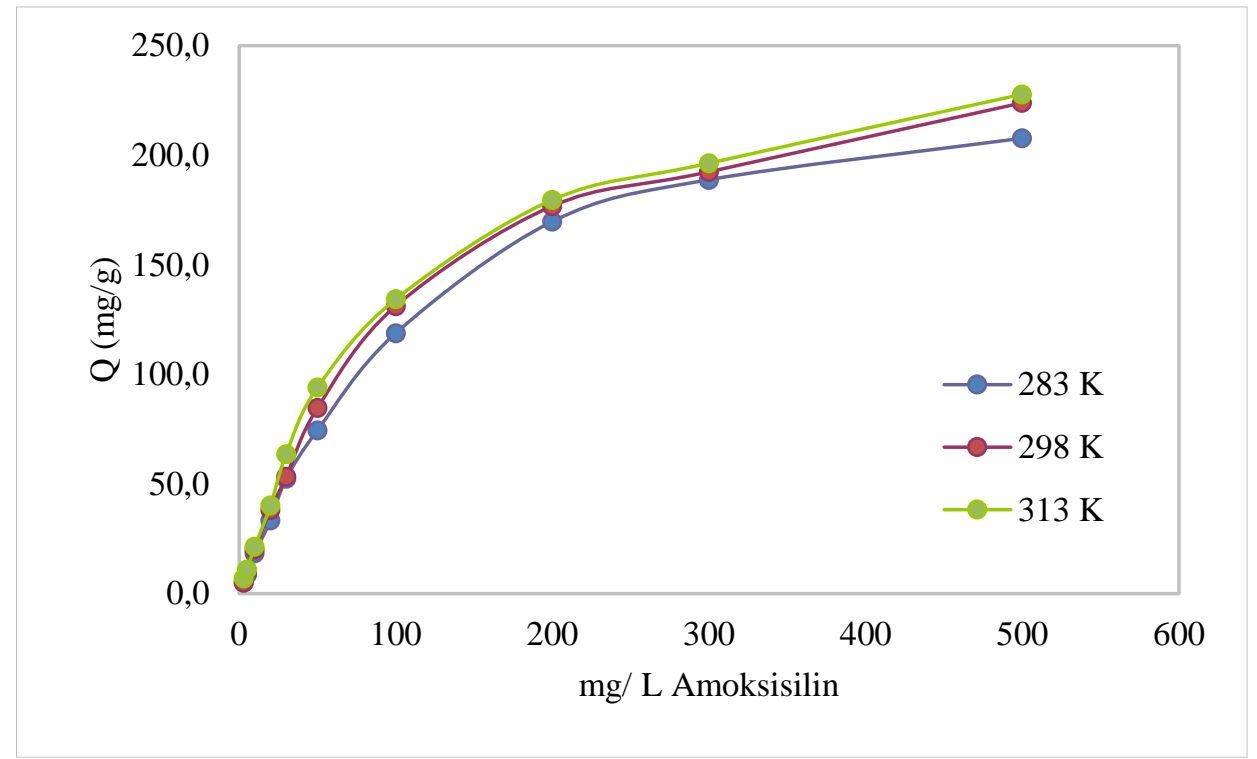

Şekil 2. Adsorpsiyona derişim etkisi.

Tablo 2. İzoterm modellerine ait parametre sonuçları

\begin{tabular}{|c|c|c|c|c|}
\hline \multirow[t]{2}{*}{$\dot{I} z o t e r m$} & \multirow[t]{2}{*}{ Parametreler } & \multicolumn{3}{|c|}{ Sicaklık } \\
\hline & & $283 \mathrm{~K}$ & $298 \mathrm{~K}$ & $313 \mathrm{~K}$ \\
\hline & $\mathrm{Q}_{\max }(\mathrm{mg} / \mathrm{g})$ & 207,8 & 223,9 & 227,8 \\
\hline \multirow{4}{*}{ Langmuir } & $\mathrm{q}_{\mathrm{m}}(\mathrm{mg} / \mathrm{g})$ & 210,13 & 224,92 & 229,04 \\
\hline & $\mathrm{K}_{\mathrm{L}}(\mathrm{L} / \mathrm{mg})$ & 0,0572 & 0,0639 & 0,0647 \\
\hline & $\mathrm{R}^{2}$ & 0,9939 & 0,9938 & 0,9905 \\
\hline & $\mathrm{R}_{\mathrm{L}}$ & $0,9622-0,0396$ & $0,9785-0,0357$ & $0,9399-0,0362$ \\
\hline \multirow{3}{*}{ Freundlich } & $\mathrm{K}_{\mathrm{F}}\left(\mathrm{L} \mathrm{mg}{ }^{(1-(1 / \mathrm{n}))} \mathrm{g}^{-1}\right)$ & 19,51 & 20,02 & 21,90 \\
\hline & $\mathrm{n}$ & 2,116 & 2,154 & 2,282 \\
\hline & $\mathrm{R}^{2}$ & 0,7882 & 0,8636 & 0,8219 \\
\hline
\end{tabular}

Üç farklı sıcaklıkta ( $283 \mathrm{~K}, 298 \mathrm{~K}$ ve $313 \mathrm{~K}$ ) incelenen adsorpsiyon eğrilerinde, sıcaklık artışının adsorpsiyon kapasitesi üzerinde $207,8 \mathrm{mg} / \mathrm{g}$ 'dan $227,8 \mathrm{mg}$ / g' a arttırıcı bir etkiye sahip olduğu görülmüştür (Şekil 2). Bu da adsorpsiyon işleminin doğasının endotermik olduğunu göstermiştir.

AMX'nin adsorpsiyon dengesini analiz etmek için lineer formdaki Langmuir ve Freundlich izoterm modelleri kullanılmıştır. İzoterm modellerinden elde edilen parametreler Tablo 2'de özetlenmiştir. Langmuir izotermi ile, üç farklı sıcaklık (283 K, $298 \mathrm{~K}$ ve 313 $\mathrm{K})$ için yüksek korelasyon katsayılarına $\left(0,9905<\mathrm{R}^{2}<0,9939\right)$ sahip deneysel veriler elde edilmiştir. Bunların yanısıra, hesaplanan AMX adsorpsiyon kapasitelerinin $\left(\mathrm{q}_{\mathrm{m}}\right)$, deneysel olarak bulunan adsorpsiyon kapasitelerine $\left(\mathrm{Q}_{\max }\right)$ yakın değerler verdiği görülmüştür. Langmuir izoterminin deneysel verilere çok iyi uyması sebebiyle, aktif karbon yüzeyin homojen olduğunu ve AMX 'nin tek tabakalı bir adsorpsiyon modeline uygun olarak yüzeyde homojen dağıldığı düşünülmektedir (Langmuir, 1916). Ayrıca $R_{L}$ olarak hesaplanan ayırma faktörü değerinin 0 ila 1 aralığında değerler alması adsorpsiyonun uygun ve istemli oluşunun farklı bir göstergesidir (Polanyi, 1932). Deneysel hesaplamalar her sıcaklık ve derişim aralığında hesaplanan $R_{L}$ değerleri $(0,0357-0,9785)$ birden düşük bulunmuştur. 


\subsection{Adsorpsiyona Süre Etkisi}

Adsorpsiyona temas süresinin etkisini incelemek için; $30 \mathrm{mg} / \mathrm{L}$ 'lik AMX çözeltilerinin $283 \mathrm{~K}, 298 \mathrm{~K}$ ve $313 \mathrm{~K}$ sıcaklıklarda yaklaşık 0,0200 g adsorban tarafından değişen sürelerde (2-180 dakika) adsorpsiyonu incelenerek, elde edilen veriler Şekil 3'de verilmiştir. Görüldüğü gibi adsorpsiyon yaklaşık 50 dakika sonunda maksimum değerine ulaşmaktadır.

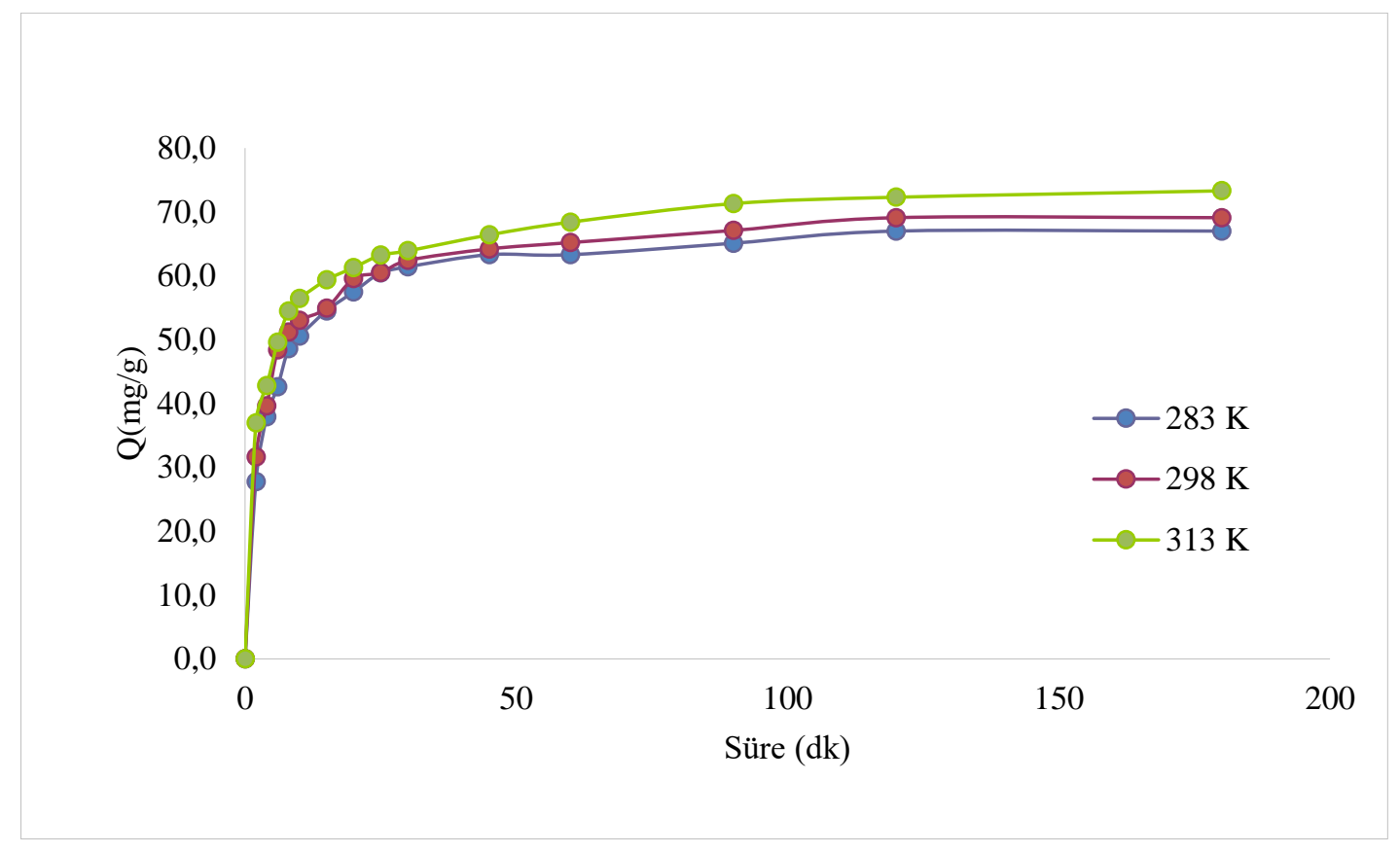

Şekil 3. Adsorpsiyon kapasitesine temas süresinin etkisi

Adsorpsiyon kapasitesinin temas süresi ve sıcaklıkla değişim verileri, kinetik modellere ait matematiksel denklemlere uygulanmıştır. Tablo 3'de yalancı birinci ve yalancı ikinci dereceli modellerin parametre sonuçları özetlenmiştir. Yalancı ikinci dereceden kinetik modelinin korelasyon katsayısının karesinin $\left(\mathrm{R}^{2}\right)$ üç farklı sıcaklık için 0,9996'dan büyük olduğu ve üç farklı sıcaklık için hesaplanan teorik adsorpsiyon kapasitelerinin $\left(\mathrm{q}_{\mathrm{e}}\right)$ deneysel adsorpsiyon kapasitesi değerlerine daha yakın olduğu görülmüsstür. $\mathrm{Bu}$ veriler ışığında, yalancı ikinci dereceden kinetik modelinin hız kontrol basamağı olarak adsorpsiyon mekanizmasıyla uyumlu olduğunu söylenebilir.

Tablo 3. Adsorpsiyona ait kinetik paramatreler

\begin{tabular}{|c|c|c|c|c|c|c|c|}
\hline \multirow{3}{*}{$\begin{array}{l}\text { Sicaklık } \\
\text { (K) }\end{array}$} & \multirow{3}{*}{$\begin{array}{l}\text { Deneysel } \\
\mathrm{q}_{\mathrm{e}}(\mathrm{mg} / \mathrm{g})\end{array}$} & \multicolumn{3}{|c|}{ Yalancı birinci derece kinetik model } & \multicolumn{3}{|c|}{ Yalancı ikinci derece kinetik model } \\
\hline & & & & & & & \\
\hline & & $k_{1} \times 10^{2}(1 /$ dak $)$ & $\mathrm{q}_{\mathrm{e}}(\mathrm{mg} / \mathrm{g})$ & $\mathbf{R}^{2}$ & $k_{2} \times 10^{3}((\mathrm{~g} / \mathrm{mg}) / \mathrm{dak})$ & $\mathrm{q}_{\mathrm{e}}(\mathrm{mg} / \mathrm{g})$ & $\mathbf{R}^{2}$ \\
\hline 283 & 67,0 & 3,57 & 27,4 & 0,8252 & 4,15 & 68,5 & 0,9999 \\
\hline 298 & 69,1 & 3,41 & 27,8 & 0,8477 & 4,04 & 70,4 & 0,9998 \\
\hline 313 & 73,3 & 2.99 & 29,1 & 0,9145 & 3.58 & 74,6 & 0,9996 \\
\hline
\end{tabular}

\subsection{Gerçek Örnek Çalışmaları}

Gerçek su numunelerindeki AMX giderim veriminin araştırılması amacıyla 20 ve $200 \mathrm{mg} / \mathrm{L}$ AMX ilave edilen çeşme suyu örneklerine farklı miktarlarda aktif karbon ilavesi ile elde edilen veriler Şekil 4'de verilmiştir. Giderim verimleri $200 \mathrm{mg} / \mathrm{L}$ AMX içeren örneklerde aktif karbon miktarının artışıla \% 40,9 dan 85,1'e yükselmiştir. Daha düşük miktarda AMX (20 mg/L) ilave edilen çeşme suyu örneklerinde ise giderim verimi 101,2 ila 109,0 aralığında olup, büyük bir farklılık göstermemiştir. Yapılan giderim çalışmalarına ait bağıl standart sapma değerleri ise $\% 0,1$ ile $\% 2,3$ aralı̆̆ında bulunmuştur. 


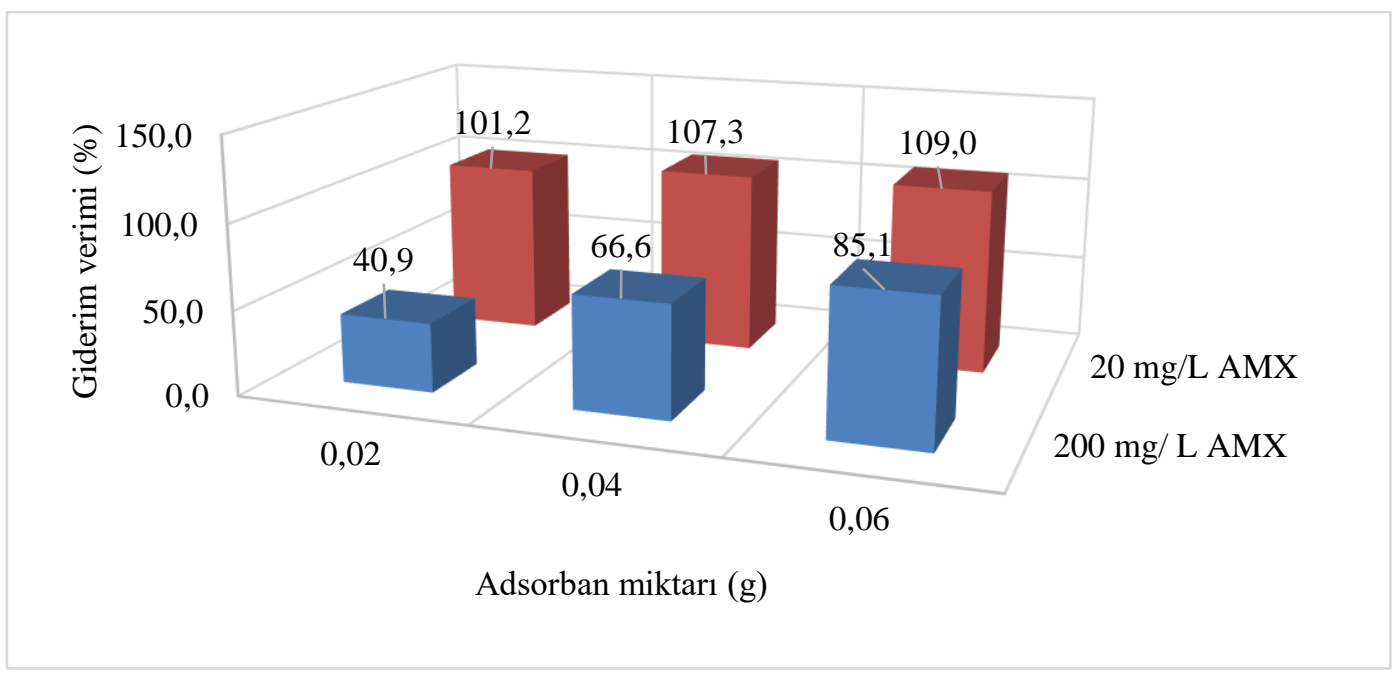

Şekil 4. Gerçek su numunesinde giderim verimleri

\section{Sonuç}

Bu çalışmada, toz formdaki ticari aktif karbonunun sulu fazdan AMX giderimi için etkinliği araştırılmıştır. Aktif karbon ile $25^{\circ}$ C'de maksimum adsorpsiyon miktarı 223,9 mg AMX / g aktif karbon olarak bulunmuştur. Adsorpsiyon işlemi endotermik karakter sergilemiştir. Adsorpsiyon verileri Langmuir izoterm modeli ve yalancı ikinci dereceden kinetik model ile uyum göstermiştir. Gerçek örneklerdeki matriks etkisi, giderim verimini etkilememiştir. Genel olarak, aktif karbonunun, çeşitli sıcaklıklar, pH değerleri ve iyonik kuvvet ortamında yeterince etkili, düşük maliyetli, AMX'in uzaklaştırılması için iyi bir adsorban olduğu kanıtlanmıştır.

\section{Kaynakça}

Al-Gheethi, A.A.S., Ismail, N. (2014). "Biodegradation of pharmaceutical wastes in treated sewage effluents by Bacillus btilis 1556WTNC". Environ. Process. 1, 459-481.

Andreozzi, R., Canterino, M., Marotta, R., Paxeus, N. (2005). “Antibiotic removal from wastewaters: the ozonation of amoxicillin", J Hazard Mater 122 (3), 243-250.

Freundlich, H., Heller, W. (1939). "The adsorption of cis- and transazobenzene”, J. Am. Chem. Soc. 61, 2228-2230.

Garoma, T,, Umamaheshwar, S.H., and Mumper, A. (2010). "Removal of sulfadiazine, sulfamethizole, sulfamethoxazole, and sulfathiazole from aqueous solution by ozonation", Chemosphere 79, 814-20.

Hayati, B., Maleki, A., Najafi, F., Gharibi, F., McKay, G., Gupta, V.K., Puttaiah, S.H., Marzban, N. (2018). "Heavy metal adsorption using PAMAM/CNT nanocomposite from aqueous solution in batch and continuous fixed bed systems", Chem. Eng. J., 346, 258270.

Hughes, S.R., Kay, P., Brown, L.E. (2016). "Impact of anti-inflammatories, beta-blockers and antibiotics on leaf litter breakdown in freshwaters", Environ Sci Pollut Res 23 (4), 3956-3962.

Langmuir, I. (1916). "The constitution and fundamental properties of solids and liquids. Part I. Solids", J. Am. Chem. Soc., 38, 22212295.

Langmuir, I. (1918). "The adsorption of gases on plane surfaces of glass, mica and platinum”. J. Am. Chem. Soc. 40, $1361-1403$.

Li, S., Li, X., Wang, D. (2004). "Membrane (RO-UF) filtration for antibiotic wastewater treatment and recovery of antibiotics", Sep Purif Technol 34, 109-114.

Li, H., Hu, J., Cao, Y., Li, X., Wang, X. (2017). "Development and assessment of a functional activated fore-modified bio-hydrochar for amoxicillin removal” Bioresource Technology 246, 168-175.

Michael, I., Rizzo, L., McArdell, C.S., Manaia, C.M., Merlin, C., Schwartz, T., Dagot, C., Fatta-Kassinos, D. (2013). “Urban wastewater treatment plants as hotspots for the release of antibiotics in the environment: a review", Water Res. 47 (3), $957-995$.

Pan, X., Deng, C., Zhang, D., Wang, J., Mu, G., Chen, Y. (2008). "Toxic effects of amoxicillin on the photosystem II of Synechocystis sp. characterized by a variety of in vivo chlorophyll fluorescence tests", Aquat Toxicol 89 (4), 207-213.

Polanyi M. (1932). "Section III- Theories of the adsorption of gases. A general survey and some additional remarks. Introductory paper to section III", Trans Faraday Soc. 28, 316-333.

Redding, A.M., Cannon, F.S., Snyder, S.A., Vanderford B.J. (2009). "A QSARlike analysis of the adsorption of endocrine disrupting compounds, pharmaceuticals, and personal care products on modified activated carbons", Water Res., 43 (15), 3849-3861.

Trovó, A.G., Melo, S.A.S., Nogueira, R.F.P. (2008). "Photodegradation of the pharmaceuticals amoxicillin, bezafibrate and paracetamol by thephoto-Fenton process - application to sewage treatment plant effluent”, J Photochem Photobiol Chem 198 (2-3), 215-220.

WHO (2014), Antibiotics Resistance Global Report on Surveillance, World Health Organization Press, Geneva.

Yu, F., Li, Y., Han, S., and Ma, J. (2016). "Adsorptive removal of antibiotics from aqueous solution using carbon materials", Chemosphere 153, 365-85.

Zandipak, R., Sobhanardakani, S. (2018). "Novel mesoporous $\mathrm{Fe}_{3} \mathrm{O}_{4} / \mathrm{SiO}_{2} / \mathrm{CTAB}-\mathrm{SiO}_{2}$ as an effective adsorbent for the removal of amoxicillin and tetracycline from water", Clean Technologies and Environmental Policy, 20, 871-885. 